\title{
Neutronics and Activation Analyses for Li/V-alloy and Flibe/V-alloy Blankets of FFHR2 with and without Beryllium
}

\author{
Zaixin LI, Teruya TANAKA ${ }^{1)}$ and Takeo MUROGA ${ }^{1)}$ \\ The Graduate University for Advanced Studies, Toki 509-5292, Japan \\ ${ }^{1)}$ National Institute for Fusion Science, Toki 509-5292, Japan
}

(Received 31 January 2007 / Accepted 3 September 2007)

\begin{abstract}
Neutronics analyses for Li/V-alloy and Flibe/V-alloy liquid blankets with and without external beryllium were performed for the FFHR2 design in order to assess the tritium breeding ratios (TBRs) and neutron shielding performances. Beryllium multiplier significantly improved the TBRs for both the Li/V-alloy and Flibe/V-alloy blankets. The shielding performance of the Li/V-alloy blanket with Be was greatly improved because the adequate TBRs can be obtained with the thinner breeding region than in the Li/V-alloy blanket without Be and the thickness of the shielding region was increased. On the other hard, the shielding performance of the Flibe/V-alloy blankets with and without external Be was comparable. It was shown that the Li/V-alloy and Flibe/V-alloy liquid blankets with and without solid Be satisfied the requirement for TBRs and shielding for the superconductor magnet of FFHR2. The activation of MHD coating of $\mathrm{Er}_{2} \mathrm{O}_{3}$ for the $\mathrm{Li} / \mathrm{V}$-alloy blankets and activation performance of the Flibe/V-alloy blankets were also investigated for the cases with and without external Be. The MHD coating of $\mathrm{Er}_{2} \mathrm{O}_{3}$ in the $\mathrm{Li} / \mathrm{V}$-alloy blankets introduced long-lived activation products. The activation of the Flibe/V-alloy blanket with external Be was comparable to that without external Be.
\end{abstract}

(c) 2007 The Japan Society of Plasma Science and Nuclear Fusion Research

Keywords: Flibe blanket, Li blanket, vanadium alloy, Be multiplier, neutronics analysis, activation analysis

DOI: $10.1585 /$ pfr.2.046

\section{Introduction}

The Force Free Helical Reactor (FFHR2) is a D-T DEMO-reactor design based on the advanced helical magnet configuration. A self-cooled molten salt Flibe blanket design for FFHR2 has been carried out using reduced activation ferritic steel (JLF-1) as the structure material [1], since Flibe has the merits on safety aspects, etc. [2]. However, the thermal efficiency of the plant is relatively low due to the high melting point of Flibe $\left(\sim 430^{\circ} \mathrm{C}\right)$ and the limit of the maximum operation temperature of JLF-1 $\left(\sim 550^{\circ} \mathrm{C}\right)$. On the other hand, vanadium alloy (V-alloy) has superior thermal-mechanical properties and can be operated up to $\sim 700^{\circ} \mathrm{C}[3]$. So the blankets with the structure material of $\mathrm{V}$-alloy have potentiality for higher thermal efficiency.

For the blankets using V-alloy, liquid $\mathrm{Li}$ and Flibe were proposed as candidate liquid tritium breeders [3-6]. Liquid $\mathrm{Li}$ is an attractive breeding material due to the high Li content, high thermal conductivity and good compatibility with V-alloy to a high temperature. However a flow of $\mathrm{Li}$ in a magnetic field would cause MHD pressure drop [3,4]. An MHD insulator coating, e.g. $\mathrm{Er}_{2} \mathrm{O}_{3}$ [7], is necessary for the Li/V blankets. Flibe possesses several attractive features such as the low electric conductivity, adequate neutron moderation and low reactivity with water and air $[6,8]$. In the Flibe/V blanket, deposition of $\mathrm{WF}_{6}$ or $\mathrm{MoF}_{6}$ into Flibe was proposed to reduce corrosive TF pro-

author'se-mail: li.zaixin@nifs.ac.jp duced as the result of transmutation of Flibe and to plate the wall with anticorrosive $\mathrm{W}$ or Mo [4,6]. Two self-cooled blanket concepts of Li/V and Flibe/V blankets without external neutron multiplier Be were adopted for FFHR2, and their Tritium Breeding Ratios (TBRs) and shielding performances were investigated $[4,5]$. Usage of external $\mathrm{Be}$ multiplier in $\mathrm{Li} / \mathrm{V}$ and Flibe/ $\mathrm{V}$ could be attractive for enhancing the tritium breeding [1,9]. Thus Flibe/V and Li/V blankets with external $\mathrm{Be}$ (Flibe/Be/V and $\mathrm{Li} / \mathrm{Be} / \mathrm{V}$ ) are very attractive. Because of the different neutron spectra, the neutronics issues for the $\mathrm{Li} / \mathrm{Be} / \mathrm{V}$ and Flibe/Be/V blankets may be different from those of Li/V and Flibe/V blankets.

The objectives of the present study are to assess impacts of the external Be on the TBRs and shielding performances of the Li/V and Flibe/V blankets for the FFHR2 design, and to investigate the associated activation issues.

\section{Procedure}

A simple torus model of FFHR2 [5] was used in the present neutronics calculation. The plasma major and minor radius of the present modified FFHR2 design, FFHR2m1 [10], is 14 and $1.73 \mathrm{~m}$, respectively. The average neutron wall loading is $1.5 \mathrm{MW} / \mathrm{m}^{2}$. The available space for the blanket is $120 \mathrm{~cm}$. The schematic radial configurations of the $\mathrm{Li} / \mathrm{Be} / \mathrm{V}$ and Flibe/Be/V blankets are shown in Fig. 1. Vanadium-alloy of $5 \mathrm{~mm}$ in thickness was 


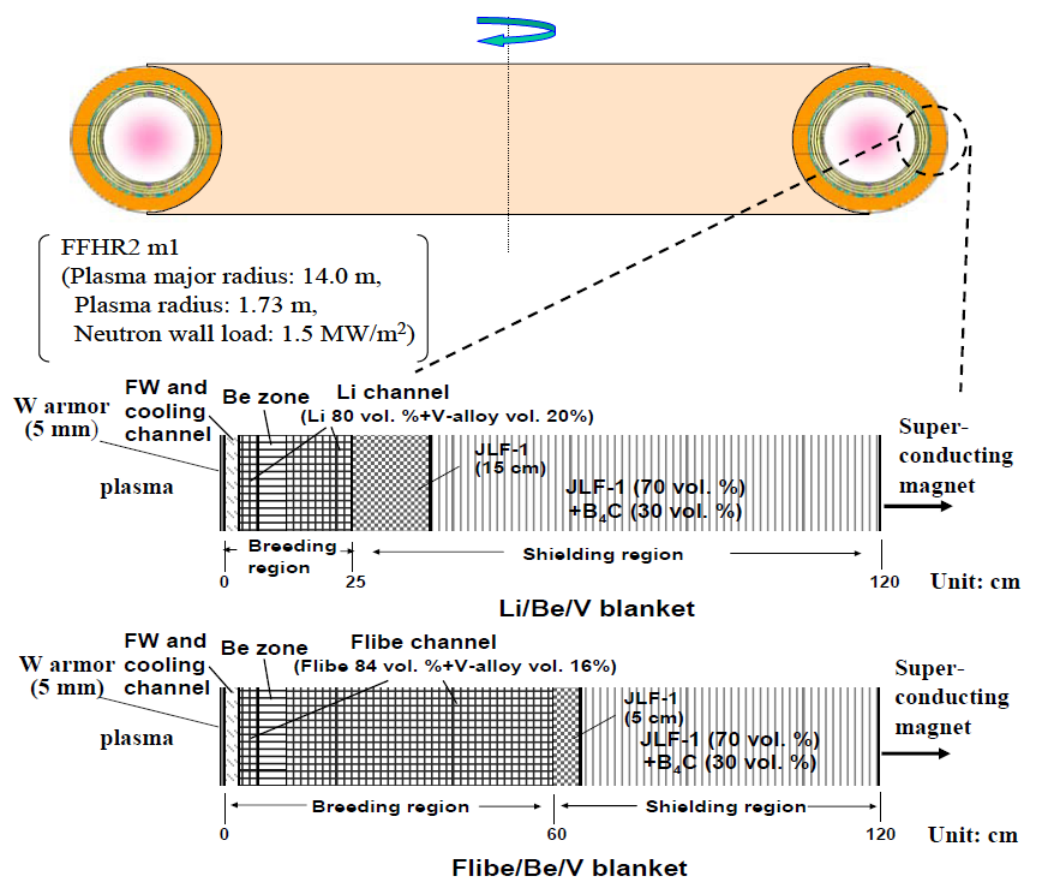

Fig. 1 Schematic radial configuration of the $\mathrm{Li} / \mathrm{Be} / \mathrm{V}$ and Flibe/Be/V blankets.

employed as the first wall (FW). A tungsten armor was attached on the surface with the thickness of $5 \mathrm{~mm}$. The mixture of JLF-1 (70 vol. \%) and $\mathrm{B}_{4} \mathrm{C}$ (30 vol. \%) was chosen for the radiation shielding according to Ref. [2]. The Li or Flibe coolant was separated by the V-alloy walls. The cooling channels in the shielding region are neglected for the calculation. The Flibe composition of $57 \mathrm{~mol} \% \mathrm{LiF}$ and $43 \mathrm{~mol} \% \mathrm{BeF}_{2}$ was chosen [5]. The achievable TBRs with $35 \%$ enrichment of ${ }^{6} \mathrm{Li}$ is near the maximum for the $\mathrm{Li} / \mathrm{V}$ and Flibe/V blankets [5]. The ${ }^{6} \mathrm{Li}$ enrichments for the Flibe/Be/ $\mathrm{V}$ and $\mathrm{Li} / \mathrm{Be} / \mathrm{V}$ blankets were fixed to $35 \%$ to examine the impact of the external $\mathrm{Be}$ on the TBRs in this study. The TBRs are enhanced by the external $\mathrm{Be}$ in both the $\mathrm{Li} / \mathrm{Be} / \mathrm{V}$ and Flibe/Be/V blankets. A $5 \mathrm{~cm}$ Be zone in a pebble form $(60 \% \mathrm{Be}+35 \%$ Flibe $+5 \% \mathrm{~V}$ alloy) or layer $(90 \% \mathrm{Be}+10 \% \mathrm{~V}$-alloy) was arranged $6 \mathrm{~cm}$ from $\mathrm{FW}$ in the Flibe/Be/V or $\mathrm{Li} / \mathrm{Be} / \mathrm{V}$ blanket as shown in Fig. 1 to provide the adequate breeding margin, while the high TBRs can be obtained for a thicker Be zone. In this study, the effects of the position and thickness of the Be zone were not investigated systematically. In addition there are some issues specific to Be such as resource limitation and irradiation effect. Thus, the optimizations of the thickness and arrangement of Be zone are still required in further study considering issues specific Be, neutronics and thermal-hydraulic performance.

For the $\mathrm{Li} / \mathrm{V}$ and $\mathrm{Li} / \mathrm{Be} / \mathrm{V}$ blankets, the electrical insulator coating of $\mathrm{Er}_{2} \mathrm{O}_{3}$ with thickness of $\sim 10 \mu \mathrm{m}$ was assumed in the interface between $\mathrm{Li}$ and $\mathrm{V}$-alloy walls to reduce the induced MHD pressure drops by the flows of $\mathrm{Li}$ in high magnetic fields.

The neutronics analyses for the breeding blankets of
FFHR2 were performed with the MCNP-4C code [11] and JENDL-3.2 file [12]. The TBRs were calculated in the model shown in Fig. 1 assuming 100\% coverage of the blankets. Figure 2 shows the calculation procedure for activation. The FISPACT-2001 code and EAF-2001 file [13] were used for the activation calculations.

\section{Results and Discussion}

\subsection{Tritium breeding and shielding perfor- mance of the $\mathrm{Li} / \mathrm{V}$, Flibe/ $\mathrm{V}, \mathrm{Li} / \mathrm{Be} / \mathrm{V}$, and Flibe/Be/V blankets}

The typical neutron spectra in the liquid blankets with and without external Be are compared in Fig. 3. All spectra were calculated at the position of $19.5 \mathrm{~cm}$ from the FW. The spectra were also used for activation analysis in the sections 3.2 and 3.3. Beryllium effectively multiplies neutrons through the $(\mathrm{n}, 2 \mathrm{n})$ reaction. In addition, Be also is an excellent neutron moderator with much lower absorption cross section for thermal neutrons compared to Li. Beryllium increased low energy neutrons significantly, especially for the $\mathrm{Li} / \mathrm{Be} / \mathrm{V}$ blanket. Thus, tritium breeding through ${ }^{6} \mathrm{Li}(\mathrm{n}, \mathrm{t})$ reaction is improved. Some calculation results of the $\mathrm{Li} / \mathrm{Be} / \mathrm{V}$ and Flibe/Be/ $/ \mathrm{V}$ blankets are compared with those of the $\mathrm{Li} / \mathrm{V}$ and Flibe/ $\mathrm{V}$ blankets in Table 1. The neutronics analysis for the Li/V blanket in Ref [5] shows that the necessary thickness of the breeding region for obtaining adequate TBRs is $\sim 55 \mathrm{~cm}$. It is possible for the $\mathrm{Li} / \mathrm{Be} / \mathrm{V}$ blanket to obtain the same TBRs with a thinner breeding region compared to the Li/V blanket due to Be. The TBRs of 1.35 can be achieved in the $\mathrm{Li} / \mathrm{Be} / \mathrm{V}$ blanket with a $25 \mathrm{~cm}$ thick breeding region. Because of the resulting increase in the shield thickness, the shielding 
Table 1 Neutronics calculation results for liquid blanket systems.

\begin{tabular}{|c|c|c|c|c|}
\hline Blanket type & $\mathrm{Li} / \mathrm{V}$ & $\mathrm{Li} / \mathrm{Be} / \mathrm{V}$ & Flibe/V & Flibe/Be/V \\
\hline $\begin{array}{c}\text { External solid neutron } \\
\text { multiplier } \\
\text { MHD coating }\end{array}$ & none & $\mathrm{Be}$ & none & $\mathrm{Be}$ \\
\hline Enrichment of ${ }^{6} \mathrm{Li}(\%)$ & 35 & $\mathrm{Er}_{2} \mathrm{O}_{3}$ & none & none \\
\hline $\begin{array}{c}\text { Thickness of breeding } \\
\text { region }\end{array}$ & 66 & 95 & 35 & 35 \\
\hline $\begin{array}{c}\text { Local Tritium } \\
\text { breeding ratios }\end{array}$ & 1.34 & 1.35 & 1.26 & 60 \\
\hline $\begin{array}{c}\text { Fast neutron } \\
\text { flux }(>0.1 \mathrm{MeV}) \\
\text { at outside of radiation } \\
\text { shield }\left(10^{9} \mathrm{n} / \mathrm{cm}^{2} / \mathrm{s}\right)\end{array}$ & 8.7 & 0.49 & 1.4 & 1.3 \\
\hline $\begin{array}{c}\text { Fast neutron fluence } \\
(>0.1 \mathrm{MeV}) \text { after } 30 \\
\text { years operation at } \\
\text { outside ofradiation } \\
\text { shield }\left(10^{18} \mathrm{n} / \mathrm{cm}^{2}\right)\end{array}$ & 8.2 & 0.46 & 1.3 & 1.2 \\
\hline
\end{tabular}

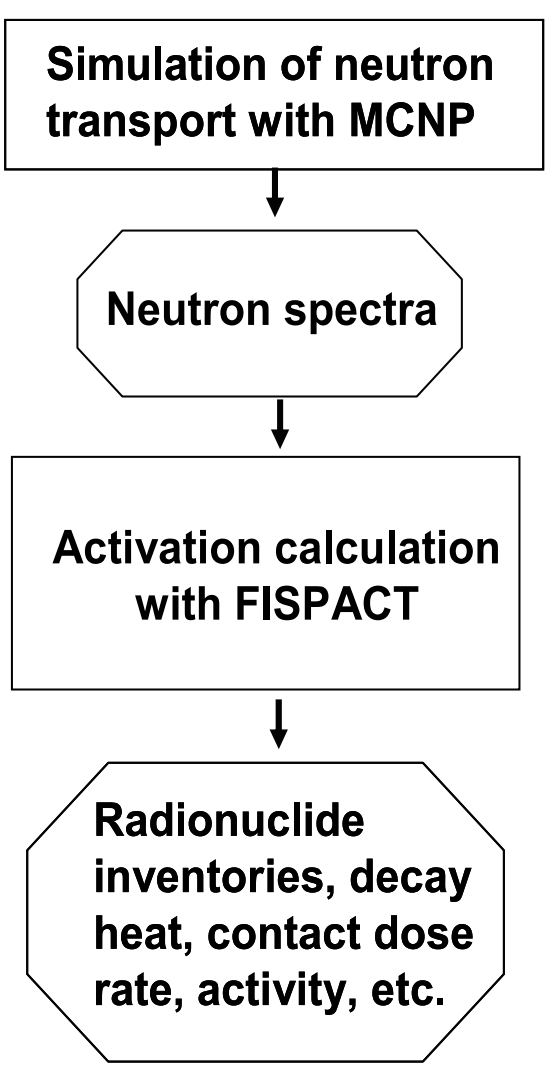

Fig. 2 Calculation procedure for activation.

property of the $\mathrm{Li} / \mathrm{Be} / \mathrm{V}$ blanket is improved significantly. The fast neutron flux $(>0.1 \mathrm{MeV})$ at outside of the radiation shield in the $\mathrm{Li} / \mathrm{Be} / \mathrm{V}$ blanket is $4.9 \times 10^{8} \mathrm{n} / \mathrm{cm}^{2} / \mathrm{s}, \sim 5.6 \%$ of that in the $\mathrm{Li} / \mathrm{V}$ blanket. However it should be noted that the heat removal from the breeding zone of $25 \mathrm{~cm}$ is not feasible. Optimization of the thickness is necessary for tritium breeding and heat control purpose.

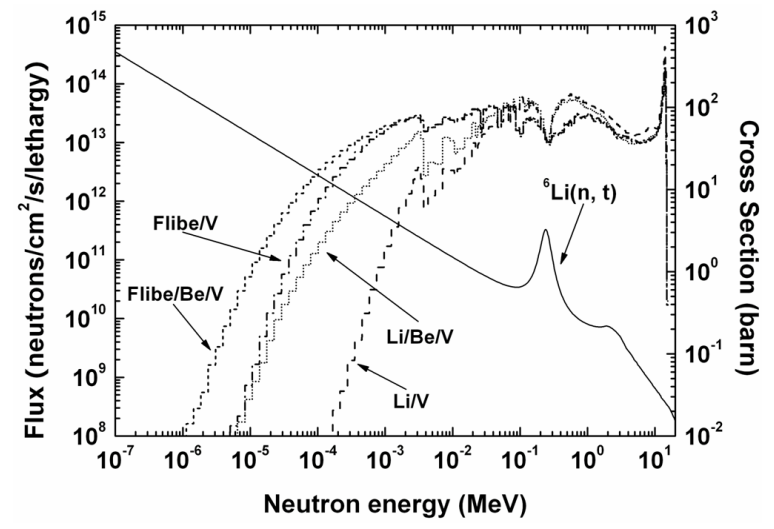

Fig. 3 Typical neutron spectra in liquid blankets and the ${ }^{6} \mathrm{Li}(\mathrm{n}, \mathrm{t})$ cross section.

With the same thickness of breeding region, the TBRs of the Flibe/Be/ $\mathrm{V}$ blanket is $\sim 10 \%$ higher than that of the Flibe/Be/V blanket. The shielding performance of the Flibe/Be/V blanket was also improved by $\sim 8 \%$.

Considering 30 years operation, the end-of-life fast neutron fluences $(>0.1 \mathrm{MeV})$ at the superconducting magnet for the $\mathrm{Li} / \mathrm{V}, \mathrm{Li} / \mathrm{Be} / \mathrm{V}$, Flibe/V, and Flibe/Be/V blankets are $8.2 \times 10^{18}, 4.6 \times 10^{17}, 1.3 \times 10^{18}$, and $1.2 \times 10^{18} \mathrm{n} / \mathrm{cm}^{2}$, respectively, which are below the limits of $10^{19} \mathrm{n} / \mathrm{cm}^{2}$ for $\mathrm{Nb}_{3} \mathrm{Sn}[14]$.

\subsection{Effect of the activation of $\mathrm{Er}_{2} \mathrm{O}_{3}$ coating in the $\mathrm{Li} / \mathrm{V}$ and $\mathrm{Li} / \mathrm{Be} / \mathrm{V}$ blankets}

In this study, the effect of the activation of $\mathrm{Er}_{2} \mathrm{O}_{3}$ coating was analyzed. Figure 4 shows the comparison of dose rate of the structural component with and without coating for the $\mathrm{Li} / \mathrm{V}$ and $\mathrm{Li} / \mathrm{Be} / \mathrm{V}$ cases. For the case with $\mathrm{Er}_{2} \mathrm{O}_{3}$ coating the dominant nuclide is ${ }^{166 \mathrm{~m}} \mathrm{Ho}$ 


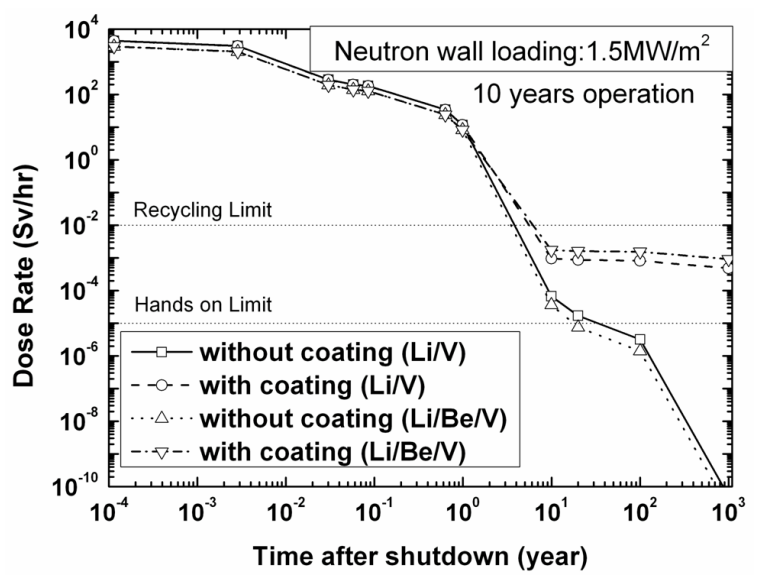

Fig. 4 Dose rate of structural component with and without $\mathrm{Er}_{2} \mathrm{O}_{3}$ coating.

$\left(\mathrm{T}_{1 / 2}, 1200 \mathrm{yr}\right)$ from $\mathrm{Er}$ in the range from several tens to a thousand years. There are three activation paths for ${ }^{166 \mathrm{~m}} \mathrm{Ho}$, namely ${ }^{166} \mathrm{Er}(\mathrm{n}, \mathrm{p}){ }^{166 \mathrm{~m}} \mathrm{Ho},{ }^{164} \mathrm{Er}(\mathrm{n}, \gamma){ }^{165} \mathrm{Er}$ (Electron Capture (EC) $)^{165} \mathrm{Ho}(\mathrm{n}, \gamma){ }^{166 \mathrm{~m}} \mathrm{Ho}$, and ${ }^{166} \mathrm{Er}(\mathrm{n}$, $2 \mathrm{n})^{165} \mathrm{Er}(\mathrm{EC}){ }^{165} \mathrm{Ho}(\mathrm{n}, \gamma){ }^{166 \mathrm{~m}} \mathrm{Ho}$. It is shown in Fig. 4 that the production of ${ }^{166 \mathrm{~m}} \mathrm{Ho}$ in the $\mathrm{Li} / \mathrm{Be} / \mathrm{V}$ blanket is about two times of that in the Li/V blanket because of the enhancement of the reactions of ${ }^{164} \mathrm{Er}(\mathrm{n}, \gamma){ }^{165} \mathrm{Er}$ and ${ }^{165} \mathrm{Ho}$ $(\mathrm{n}, \gamma)^{166 \mathrm{~m}} \mathrm{Ho}$ with low energy neutrons in the Li/Be/V blankets. It is shown that $\mathrm{V}$-alloy is a good low activation material and can be recycled by hands-on operation after $\sim 20$ years cooling, while V-alloy with the coating needs shielding for recycling even after 1000 years cooling. It costs much more in the recycling of V-alloy structural materials with $\mathrm{Er}_{2} \mathrm{O}_{3}$ coating than that of the bare V-alloy.

\subsection{Activation of Flibe/ $\mathbf{V}$ and Flibe/Be/V blankets}

Dose rate of V-alloy and Flibe vs. cooling time in the Flibe/V and Flibe/Be/V blankets are plotted in Fig. 5. The activation of the Flibe/Be/V blanket is comparable to that of the Flibe/V blanket. After 10 years operation, V-alloy meets the hands-on requirement at the cooling time of several tens years. Flibe is re-circulated along the coolant channel inside and outside the blankets at the operation time. Here 10 days continuous irradiation was assumed for the activation analysis of Flibe as a simplification of the periodical irradiation in the blanket and cooling at outside of the blanket, respectively. The activity in Flibe decays to negligible level sooner than that in the structural material of V-alloy. The dominant radionuclide in Flibe is ${ }^{18} \mathrm{~F}\left(\mathrm{~T}_{1 / 2}\right.$, $1.83 \mathrm{hr}$ ) produced by ${ }^{19} \mathrm{~F}(\mathrm{n}, 2 \mathrm{n}){ }^{18} \mathrm{~F}$ reaction with the high threshold energy. The induced dose rate from Flibe in the Flibe/Be/V is slightly lower than that in the Flibe/V due to the lower neutron flux at high energy.

\section{Conclusion}

The neutronics analysis was performed for the $\mathrm{Li} / \mathrm{V}$,

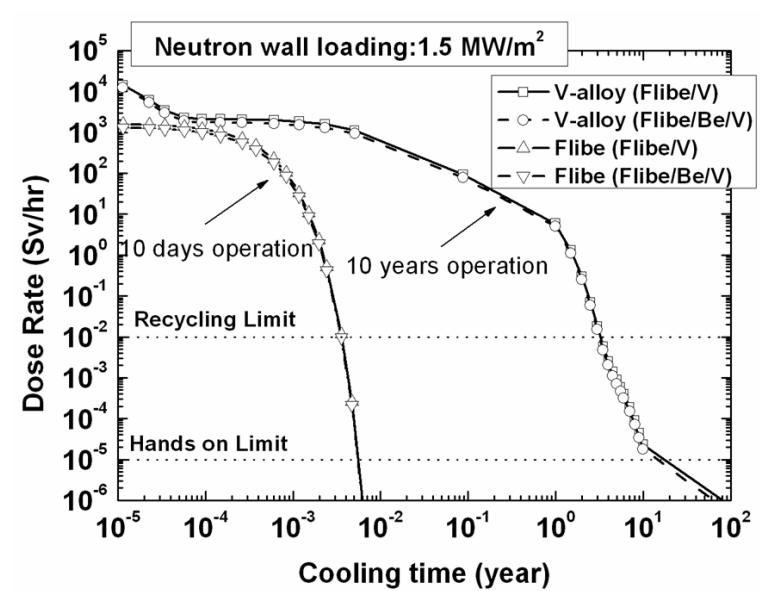

Fig. 5 Dose rate of Flibe with 10 days operation and V-alloy with 10 years operation vs. cooling time.

$\mathrm{Li} / \mathrm{Be} / \mathrm{V}$, Flibe/V, and Flibe/Be/V blankets designed for FFHR2. The external solid beryllium in the blankets significantly improved the tritium breeding performance. The $\mathrm{Li} / \mathrm{Be} / \mathrm{V}$ blanket achieved the same TBRs as the Li/V blanket with thinner breeding region. Thus the shielding performance of the $\mathrm{Li} / \mathrm{Be} / \mathrm{V}$ was improved due to the thicker shielding region. The tritium breeding and shielding performances of the Flibe/Be/V blanket were improved by $\sim 10 \%$ and $\sim 8 \%$, respectively, with the same thickness of shielding as that in the Flibe/V blanket.

The activation of the electrically insulating coating of $\mathrm{Er}_{2} \mathrm{O}_{3}$ could influence the long-term activation property of the structural component. It costs much more in the recycling of V-alloy structural materials with $\mathrm{Er}_{2} \mathrm{O}_{3}$ coating than that of the bare V-alloy. Flibe and V-alloy show low activation property in the Flibe/V and Flibe/Be/V blankets. The activation of the Flibe/Be/V blanket is comparable to that of the Flibe/V blanket.

\section{Acknowledgments}

This study was supported by the NIFS budget codes NIFS05KFRF017 and NIFS06GCFF002.

[1] A. Sagara et al., Fusion Eng. Des. 49-50, 661 (2000).

[2] A. Sagara et al., Fusion Eng. Des. 29, 51 (1995).

[3] R.F. Mattas et al., Fusion Eng. Des. 39-40, 659 (1998).

[4] T. Muroga et al., Fusion Eng. Des. 81, 1203 (2006).

[5] T. Tanaka et al., Fusion Sci. Technol. 47, 530 (2005).

[6] D.-K. Sze, Fusion Technol. 10, 875 (1986).

[7] Z. Yao et al., Fusion Eng. Des. 75-79, 1015 (2005).

[8] M.Z. Youssef et al., Fusion Sci. Technol. 69, 205 (2003).

[9] I.R. Kirillov et al., Fusion Eng. Des. 39-40, 669 (1998).

[10] A. Sagara et al., Nucl. Fusion 45, 258 (2005).

[11] J.F. Briesmeister, MCNP-A general Monte Carlo n-particle transport code, LA-12625-M (2000).

[12] T. Nakagawa et al., J. Nucl. Sci. Technol. 32, 1259 (1995).

[13] R.A. Forrest, UKAEA Report, UKAEA FUS 449 (2001).

[14] Mohamed E. Sawan et al., Fusion Technol. 10, 741 (1986). 